\title{
ACCiÓN COLECTIVA Y POLÍTICAS PÚBLICAS. EL CASO DE LA MASACRE DEL I 6 DE MAYO DE I 998
}

Flor Manuelita Barrios Rodríguez* Claudia Milena Quijano Mejía** Luis Ricardo Soler Madrid ${ }^{* * *}$

\section{Resumen}

En 1998 sucedió la masacre del 16 de mayo en Barrancabermeja, que significó el ingreso de los grupos paramilitares al territorio y el incremento de la violencia. Como respuesta, las organizaciones sociales presentes en la ciudad realizaron diversas acciones colectivas, que trascendieron este hecho a un tema de interés nacional e internacional. El presente artículo es el resultado de una investigación triangular que utilizó técnicas cuantitativas y cualitativas de recolección de información. El análisis se realizó desde el enfoque del mesoanálisis, a través del cual se estudió la definición de la masacre como un problema público, y su inserción dentro del ciclo de política pública, que fue visibilizado por la acción colectiva y los medios de comunicación, generando un efecto búmeran.

Palabras clave: acción colectiva, políticas públicas, medios de comunicación, buen gobierno.

* Maestría en Gobierno y Políticas Públicas. Profesional del Centro de Estudios Regionales (CER). Barrancabermeja (Colombia).manuelita.barrios@cer.org

** Maestría en Integración de América Latina. Docente tiempo completo, Universidad Industrial de Santander (UIs). Bucaramanga (Colombia).uyuni.48@gmail.com

*** Profesional en Ciencia política. Profesional pNud. Bogotá (Colombia). ricardo.soler.madrid@gmail.com Recibido: 10/07/2016/ Modificado: 16/11/2016/ Aceptado: 20/11/2016.

Para citar este artículo

Barrios Rodríguez, F. M., Quijano Mejía, C. M. y Soler Madrid, L. R. (2017). Acción colectiva y políticas públicas. El caso de la masacre del 16 de mayo de 1998. Opera, 20, pp. 55-83.

DOI: https://doi.org/10.18601/16578651.n20.04 
COLLECTIVE ACTION AND PUBLIC POLITICS. THE MASSACRE OF 16TH MAY OF 1998 CASE

\section{Abstract}

In 1998 succeeded the Massacre of 16th May in Barrancabermeja, this meant entering territory paramilitary groups and increasing violence. In response organizations presents in the city made several collective actions that became a national and international issue. This article is the result of a triangular research using quantitative and qualitative data collection techniques. The analysis was conducted from the perspective of meso-analysis, through which the definition of the massacre was studied as a problem and its insertion into the cycle of public policy, which was made visible by collective action and the media, generating a boomerang effect.

Key words: Collective action, public politics, social media, good government.

\section{INTRODUCCIÓN}

El municipio de Barrancabermeja está ubicado sobre la parte media del río Magdalena, y algunos académicos y líderes sociales lo consideran capital natural de la región del Magdalena Medio. Al respecto, la Corporación Desarrollo y Paz del Magdalena Medio (CDPMM) ha definido que este territorio está compuesto por 64 municipios que hacen parte de ocho departamentos -con mayor concentración en Antioquia, Bolívar, Boyacá, Cesar y Santander; y menor medida en Caldas, Cundinamarca y Tolima-.
Este municipio ha sido históricamente fuente de empleo y polo de desarrollo alrededor de la industria petrolera, con una marcada tradición sindicalista. Sin embargo, ha sido víctima de la violencia producto del conflicto entre los diferentes grupos armados ilegales para lograr el control territorial y el acceso ilegal a las rentas del petróleo, mediante extorsiones, vacunas, cartel de la gasolina, entre otros.

La masacre del 16 de mayo de 1998 fue un hito histórico que marcó el incremento de la violencia armada en la región. En el periodo 1998-2001, Barrancabermeja registró el mayor número de homicidios, con un total de 1.836 personas asesinadas (Dávila, 2010, citado en Barrios, 2012). Esta situación de violencia convergió en acciones colectivas que han buscado, en particular, acompañar a las víctimas de la violencia, y han logrado influir en las políticas públicas de seguridad y convivencia ciudadana en los distintos gobiernos locales e incluso nacionales.

Al respecto, es importante señalar que uno de los objetivos de las acciones colectivas es influir en la elaboración de políticas públicas que permitan satisfacer sus demandas. Sin embargo, hasta el momento, los estudios sobre el tema han dado mayor importancia a la manera como estas se constituyen, que al logro de sus fines (López, 2012). Como señala Ann, "La investigación en políticas públicas rara vez ha tratado los movimientos sociales como agentes activos para el cambio de políticas" (citado en Favela, 2006, p. 20).

La incidencia de las acciones colectivas en las políticas públicas de seguridad y convivencia ciudadana en Barrancabermeja 
en el periodo 1998-2014, se estudió desde el enfoque de análisis de los movimientos sociales exitosos, que según Klandermans se identifican por lograr "el incremento de la respuesta del sistema político a las demandas de los actores, sea que consigan abrir un sistema cerrado o que logren crear oportunidades para sí mismos y para otros" (citado por López, 2012, p. 171).

De esta manera, se analizó si las acciones colectivas alrededor de la masacre del 16 de mayo tuvieron dos tipos de éxito: uno, procedimental, que logra abrir canales de participación y reconocimiento legítimo a los grupos demandantes, que además tiene una incidencia en el ciclo de políticas públicas. Otro, sustancial, que puede producir cambios en estas porque interviene en la hechura de políticas públicas (proactivas) o logra vetar algunas (reactiva).

Las variables de análisis que se utilizaron tanto para recolectar, sistematizar y analizar la información primaria y secundaria fueron: 1) identificación de los actores involucrados en el conflicto (víctimas, victimarios, líderes sociales, actores políticos; 2) contexto social en Barrancabermeja; 3) el evento de la masacre, con el fin de reconstruir la memoria de hechos que acontecieron desde las voz de las víctimas y los medios de comunicación; 4) las acciones colectivas (marchas, paros, pronunciamientos); 5) el número de respuestas de los gobiernos nacional, departamental y municipal (pronunciamientos, acuerdos, decretos, leyes); 6) la incidencia procedimental o sustantiva de la acción colectiva.

La investigación se llevó a cabo desde el análisis cualitativo-cuantitativo en el que:
1) se realizó observación participante, a partir del acompañamiento a las reuniones del Colectivo 16 de Mayo de 1998, compuesto por los familiares de víctimas letales de este suceso, con el fin de realizar su proceso de consolidación en el municipio; 1) se llevaron a cabo diez entrevistas a profundidad a los familiares de las víctimas letales y líderes sociales reconocidos en el municipio; 2) se realizó un análisis de contenido clásico de los archivos de periódico, con el objetivo de convertir datos cualitativos en cuantitativos para comprobar las hipótesis, lo que implicó una codificación preliminar (Valles, 1999); 3) se identificaron documentos que sustentan la incidencia de las acciones colectivas en la formulación de políticas públicas en el periodo 1998-2014 -planes de desarrollo, leyes, decretos municipales, documentos del Consejo Nacional de Política Económica y Social (Conpes), entre otros-, en búsqueda de nuevas categorías que permitieran fundamentar las hipótesis.

\section{Mesoanálisis: el posicionamiento del problema en la agenda sistémica}

Los fundamentos teóricos de la investigación se definieron desde el enfoque del mesoanálisis (Parsons, 2007), a través del cual se analizó el proceso en el que la masacre del 16 de mayo se insertó en la agenda sistémica local y nacional, como un fenómeno social visibilizado por la presión de los movimientos sociales y por la importancia que los medios de comunicación le dieron a este hecho convirtiéndolo en noticia.

Parsons (2007), en su texto Políticas Públicas. Una introducción a la teoría y práctica 
del análisis de políticas públicas señala que estas se refieren a la forma como se definen y construyen los problemas y llegan a la agenda política, al mismo tiempo que responde el cómo, por qué y para qué los gobiernos toman determinadas medidas. Señala también que el mesoanálisis se concentra en el vínculo entre las etapas de definición de los problemas, agenda, proceso de toma de decisiones e implementación de las políticas públicas. Además, el autor menciona tres enfoques para el análisis de los problemas sociales: el positivista, el sociológico y el de los medios de comunicación masiva. En esta investigación se tomaron como referencia los dos últimos.

El enfoque sociológico analiza los problemas desde la fenomenología. Desde esta perspectiva, Mauss (citado por Parsons, 2007) considera que son los movimientos sociales los que facilitan el tránsito para que una situación indeseable pase de ser un tema a un problema público. El proceso de visibilizar los problemas también ha sido estudiado mediante la accountability social (O'Donnell, 2002; Peruzzoti, 2006), que se refiere al resultado de un cambio social en el que los representados ya no permanecen pasivos ante las decisiones políticas sino, por el contrario, tienen un rol activo de seguimiento de las diferentes políticas públicas.

A partir de esto, se considera que el enfoque de los medios de comunicación es fundamental para esta investigación, ya que según Parsons (2007) son los que eligen lo que les parece digno de convertirse en noticia, además, incluyen o excluyen los asuntos, sucesos e ideas. Por otra parte, desde la perspectiva de la accountability social, el periodismo cumple la labor de aliado para visibilizar los reclamos cívicos, de denuncia, o investigación de información confidencial. De esta manera, "la visibilidad mediática de las denuncias y demandas cívicas es crucial para lograr movilizar convicciones en la opinión pública y para ejercer una presión efectiva sobre las autoridades" (Peruzzoti, 2009, p. 8). En consecuencia, son los medios de comunicación los que a partir de un incidente o suceso inesperado como la masacre del 16 de mayo, pueden definir el contexto e influir en la agenda pública (Parsons, 2007).

Según Cobb y Elder (1972, citado por Parsons, 2007), más que la agenda se defina por detonadores internos (catástrofes naturales, acontecimientos humanos inesperados) y externos (actos bélicos, conflictos internacionales, etc.), debe haber un vínculo entre estos y la agenda que tenga la capacidad de que el tema sea un punto dentro de esta. Desde este punto de vista, los autores diferencian dos tipos de agenda: la sistémica y la institucional. La primera se compone por "todos los temas percibidos por los miembros de una comunidad política como asuntos que merecen la atención pública y que entrañan cuestiones pertinentes a la legítima jurisdicción de la autoridad gubernamental en funciones" ( $p$. 82). Y la segunda por "la serie de puntos explícitamente seńalados para la consideración activa, de los tomadores de decisiones" (p. 82).

Para la visibilización de un problema se requiere de individuos con habilidades de persuasión, para convocar a otros a realizar acciones colectivas que llamen la atención del Estado. Uno de los aliados fundamentales para ello son los medios de comunicación, los 
cuales son los encargados de posicionar en la agenda mediática los hechos más relevantes y de interés para la opinión pública, para lo cual analizan el grado de impacto de la problemática. De esta manera, el proceso de agendar el problema es sistémico, es decir, no se da a partir de los intereses del Estado, sino a raíz de los planteamientos de la comunidad que recurre a la acción colectiva y al establecimiento de un discurso ideológico que llame la atención de los medios de comunicación y que permita la visibilización del problema. En otras palabras, es un proceso de accountability social en el que los actores son los que demandan la actuación del Estado (figura 1).

\section{Incidencia de la acción colectiva contenciosa en las políticas públicas}

La acción colectiva contenciosa se identifica por ser usada por personas que se caracterizan por carecer de acceso a las instituciones, actuar en nombre de reivindicaciones nuevas y representar una amenaza fundamental para otros por su forma de obrar. En este sentido, Tarrow (1998) plantea que el proceso de los movimientos sociales inicia con los desafíos colectivos que se caracterizan por interrumpir u obstruir las actividades de otros, así como crear incertidumbre, con el fin de ser un referente de sus seguidores y llamar la

FIGURA 1. PROCESO DE CONFORMACIÓN DE AGENDA SISTÉMICA

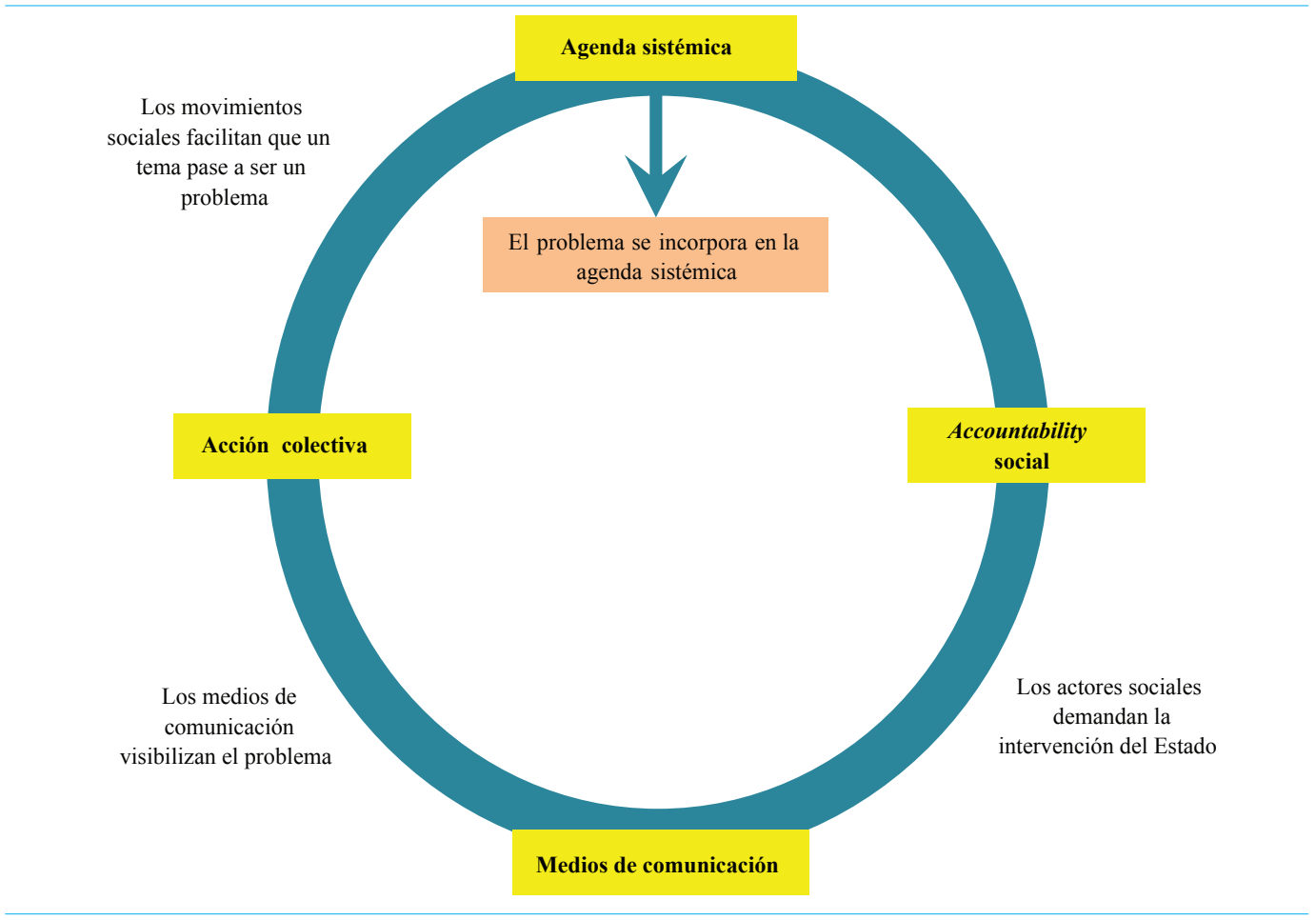

Fuente: elaboración propia. 
atención de los oponentes. Y continúa con la utilización de redes sociales, objetivos comunes y marcos culturales que se basen en el planteamiento de exigencias comunes que contengan intereses y valores compartidos, lo suficientemente importantes como para que la gente asuma sus riesgos. En consecuencia, debe haber un reconocimiento claro de cuáles son estos intereses.

Para Keck, Sikkink y Murillo (1999), estas redes no solo se constituyen desde el nivel local, sino que incluso pueden trascender al ámbito internacional en lo que han denominado redes transnacionales de cabildeo e influencia que se organizan a partir de principios y valores compartidos. En estas participan actores que trabajan internacionalmente, quienes "transmiten ideas, las insertan en los debates políticos, presionan para que se creen regímenes internacionales y vigilan la aplicación de las normas y reglas internacionales, al tiempo que tratan de influir en la política interna" (p. 405).

Este tipo de redes tienen más probabilidad de aparecer cuando las relaciones entre los grupos locales y sus gobiernos se han fragmentado, de tal modo que los grupos locales prefieren buscar apoyo de organismos internacionales para ejercer presión desde el exterior sobre sus propios gobiernos. Así, retornan al país las demandas internas pero ahora presentadas como presiones externas, a esto Keck et al. (1999) denominan el efecto búmeran.

Expuesto lo anterior, es necesario ahondar en los resultados, consecuencias e impactos que pueden hacer que una acción colectiva tenga éxito a la hora de influir en las políticas públicas. Para analizar sus resultados Giugni (citado por López, 2012) propone tres procesos: 1) incorporación, que tiene efectos en los procedimientos; 2) transformación, que busca tener efectos estructurales sustanciales; 3) democratización, que busca tener efectos en los regímenes.

En esta investigación se analizaron tanto el éxito procedimental como el sustancial proactivo. En el primer caso, con el fin de estudiar el proceso mediante el cual las organizaciones sociales logran acceder a las instituciones, a través de la acción colectiva; en el segundo, para determinar su incidencia en las políticas públicas. Estas fases son acordes con el ciclo de políticas públicas y se dividen de la siguiente manera: primero, acceso, el cual se da cuando la acción colectiva logra acceder a los canales institucionales de decisión. Segundo, agenda, que es el posicionamiento de un tema en la agenda pública. Tercero, adopción del contenido de las propuestas por las instituciones. Cuarto, implementación de las políticas adoptadas (López, 2012).

\section{Acción colectiva y políticas públicas de seguridad y convivencia ciudadana}

Una de las características significativas del contexto en el que ocurrió la masacre del 16 de mayo es la violencia política como resultado de la confrontación entre los grupos armados de izquierda y derecha (guerrilleros y paramilitares), los primeros aliados ideológicos de las protestas, mientras que los segundos un fuerte opositor. González (2006) señala que este tipo de contextos tienen tres dimensiones que los caracterizan: primero, la configuración territorial, en la que las acciones 
violentas se pueden dar de manera desigual en el territorio conformando así una segregación socioespacial. Segundo, los actores sociales que son afectados directa e indirectamente por la violencia, y pueden tener tres tipos de comportamiento: acomodarse, refugiarse o resistir. Por último, en estos contextos se cuestiona la soberanía estatal, según González:

...ello podría implicar que en algunas regiones y territorios, especialmente en aquellos atravesados por el conflicto abierto, la soberanía del Estado permanezca en vilo, en disputa, en tensión de desafío permanente, bien desde poderes armados de diferente signo, bien desde grupos sociales cuyas reglas de vida se rigen por órdenes alternativos diferentes y a veces antagónicos con lo legal, hasta por ciudadanos corrientes que desacatan el orden normativo en sus interrelaciones privadas y públicas (2006, p. 38).

La voluntad de no sometimiento al Estado se da tanto por la lucha de la población por inclusión social, como por la resistencia, en este caso de los grupos armados ilegales, a una autoridad legal, creándose así posibles escenarios de confrontación y combate por medio de las armas. Esto sucede cuando el Estado no ha logrado constituirse como generador del orden y de la cohesión social (González, 2006). Por ejemplo, en el caso de la conformación de grupos paramilitares en Colombia, con fines de establecer estrategias de control social.

Además, la acción colectiva que se da en contextos de violencia reproduce acciones violentas con el fin de hacer visibles sus agravios; según Tarrow, "la mayor parte de la acción colectiva se centra en la violencia, o en la amenaza de la violencia, porque era la forma de acción colectiva que más fácilmente podían emprender grupos locales, aislados, analfabetos y enfurecidos" (1998, p. 139).

Teniendo en cuenta el contexto de violencia en el que se dio la masacre del 16 de mayo de 1998, se analizó la incidencia de la acción colectiva en las Políticas Públicas de Seguridad y Convivencia Ciudadana, el primer término definido como "la protección universal a los ciudadanos frente a aquellos delitos y contravenciones que afecten su dignidad, su seguridad personal y la de sus bienes, y frente al temor a la inseguridad" (DNP, 2011). Mientras que el segundo se refiere a "la promoción del apego y la adhesión de los ciudadanos a una cultura ciudadana basada en el respeto a la ley, a los demás y a unas normas básicas de comportamiento y de convivencia social" (DNP, 2011).

\section{Enfoques de implementación de políticas públicas}

La implementación de las políticas públicas es el proceso de transformar en hechos las políticas públicas, y es, en sí, "la determinante definitiva del resultado" (Pressmann y Wildavsky, 1978, p. 327, citado por Roth, 2002), la cual se define como "la fase de una política durante la cual se generan actos y efectos a partir de un marco normativo de intenciones, de textos o de discursos" (Meny y Thoening, 1922, p. 159, citado por Roth, 2002).

La implementación de las políticas públicas se puede analizar desde dos enfoques: 1) el enfoque clásico de la administración racional, entendido como el modelo ideal para un ente 
ejecutor de las decisiones que, además, es el tipo ideal de top down; 2) el enfoque del buen Gobierno, que considera que las decisiones políticas tratan de construir escenarios de participación de las organizaciones sociales.

En síntesis, la acción colectiva contenciosa es utilizada por los actores sociales, como una oportunidad de incidir de manera exitosa en la formulación de las políticas públicas, que se articulan en redes locales con trascendencia en el ámbito internacional, generando un efecto búmeran. Por otra parte, el éxito de la incidencia de los movimientos sociales en la formulación de las políticas públicas se analizó desde la perspectiva procedimental y sustantiva. Por último, se consideró que la implementación de las políticas públicas de seguridad y convivencia ciudadana se da desde el enfoque de administración racional y buen gobierno (figura 2).

\section{FORMACIÓN Y CONSOLIDACIÓN DE LAS ORGANIZACIONES SOCIALES EN BARRANCABERMEJA}

La formación y consolidación de las organizaciones sociales en el municipio de Barrancabermeja se dio en tres momentos: primero, las huelgas de los trabajadores de la Troco, por las malas condiciones laborales y la evidente segregación laboral y social; se-

FIGURA 2. FUNDAMENTO TEÓRICO

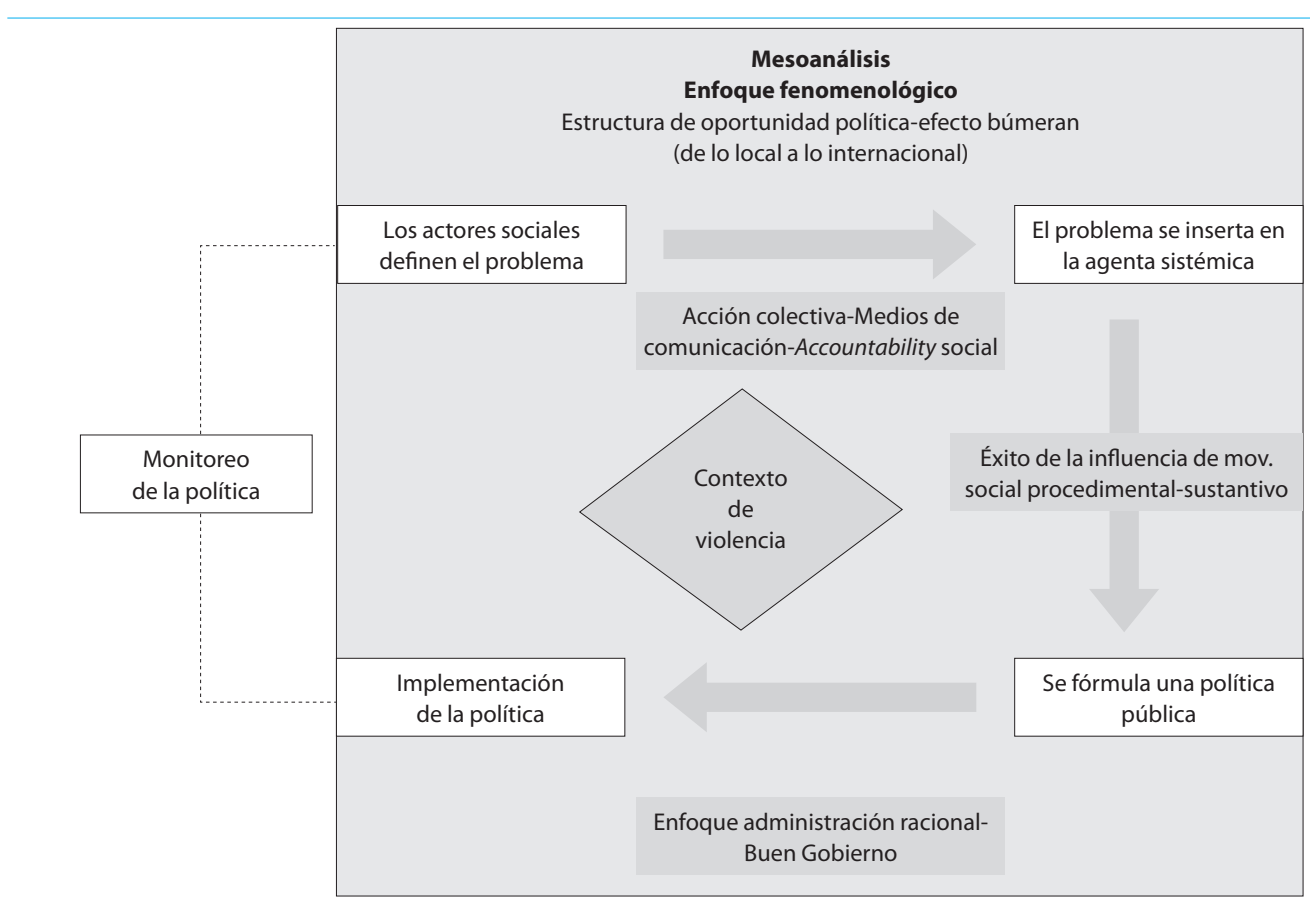

Fuente: elaboración propia. 
gundo, el surgimiento de los grupos armados guerrilleros y el acompañamiento que estos realizaron a los paros laborales y cívicos en la década de los sesenta; y tercero, los frecuentes paros cívicos que buscaron mejorar las condiciones de vida de los habitantes de los barrios nororientales en las décadas de los setenta y ochenta, mediante la demanda de servicios públicos, infraestructura, y la construcción de un hospital (Barrios, 2012).

El contexto de violencia en el municipio se manifestó en un "estado de guerra", caracterizado por la insuficiente presencia estatal para ejercer el poder institucional, permitiendo que los grupos armados ilegales crearan sus propias normas y se negaran a subordinarse a las estatales (González, 2006, p. 36). Este estado de guerra se dio por tres razones: uno, la configuración territorial desigual, marcada por la segregación socioespacial; dos, los actores sociales afectados por la violencia decidieron resistir; y tres, la ausencia de soberanía estatal permitió que el territorio estuviera en permanente disputa entre grupos armados guerrilleros y paramilitares, dando lugar a la confrontación armada (p. 38). Esto se dio en tres etapas: primera, la estigmatización de la población barrameja como colaboradora de la guerrilla; segunda, la presencia de la Red 07 de Inteligencia de la Armada, creada por el Estado para combatir de manera ilegal a la guerrilla; y tercera, el ingreso de los grupos paramilitares al municipio.

La confrontación entre los grupos armados ilegales seguía lógicas de actuación diferentes: por un lado, las acciones violentas de los grupos guerrilleros estaban dirigidas a realizar daños a bienes civiles mediante la quema de vehículos y el sabotaje a la infraestructura energética-petrolera. Por otro lado, los grupos paramilitares -en ocasiones con el apoyo de la fuerza pública- actuaron como fuerza represiva contra la población, siendo los responsables del mayor número de asesinatos selectivos en el periodo 1981-2001.

Los daños a bienes civiles son "los causados a bienes materiales que no son objetivo militar y que no deben ser objeto de ataque o represalia" (Centro Nacional de Memoria Histórica, s. f.). En la figura 3 se puede evidenciar que la mayoría de daños a bienes civiles durante el periodo de 1988-2011, fueron causados por los grupos guerrilleros. En la figura 4 se muestran los tipos de daños causados por los grupos armados ilegales entre los que se encuentran: 85 quemas de vehículos (33 de buses de transporte público, principalmente entre 1991 y 1997), 55 acciones de sabotaje a la infraestructura energética (en especial oleoductos, con mayor frecuencia entre 1991 a 1994), y 5 atentados a vivienda urbana por paramilitares entre 2008 y 2011. Después de ocurrida la masacre del 16 de mayo disminuyeron considerablemente los daños a bienes civiles realizados por los grupos guerrilleros, como resultado de la estrategia de los paramilitares para desarticularlos.

Se entiende por masacre "el homicidio intencional de 4 o más personas en estado de indefensión en iguales circunstancias de modo, tiempo y lugar, y que se distingue por la exposición pública de la violencia" (Centro Nacional de Memoria Histórica, s. f.). En el periodo 1980-2012 se registraron 43 masacres en el municipio de Barrancabermeja, de las cuales 27 fueron realizadas por paramilitares, 
FIGURA 3. DAÑOS A BIENES CIVILES PERPETRADOS POR GRUPOS ARMADOS ILEGALES, 1988-2011

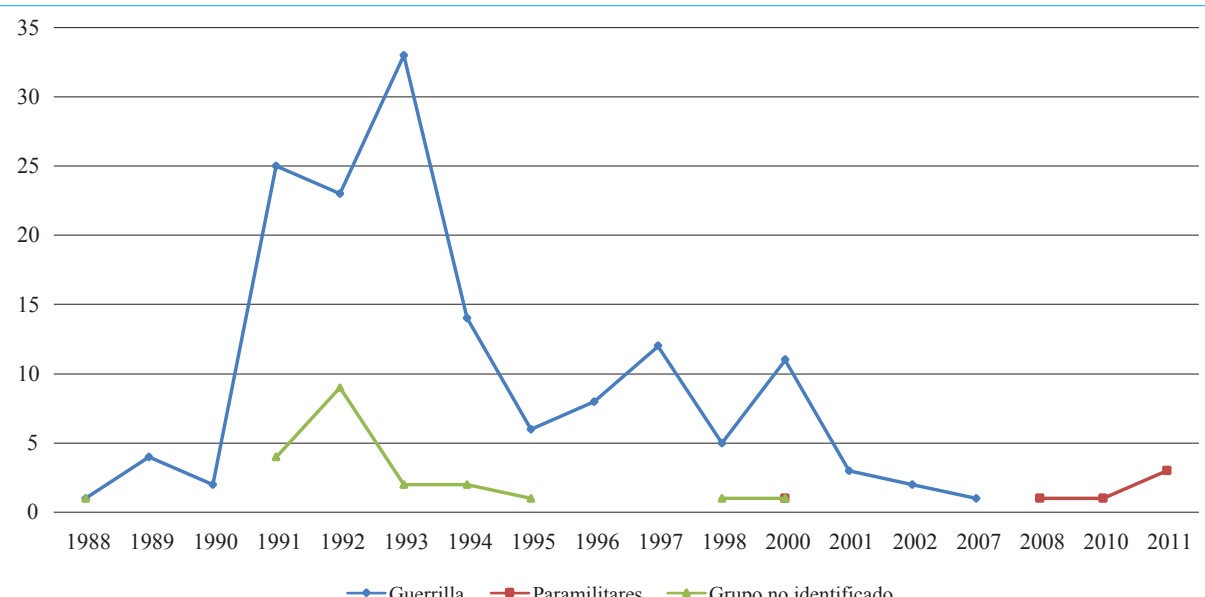

Fuente: elaboración propia, a partir de la base de datos Daños a Bienes, 1980-2012, de los Grupos Armados, del Centro de Memoria Histórica (s. f.).

FIGURA 4. TIPO DE DAÑOS A BIENES, 1988-2011

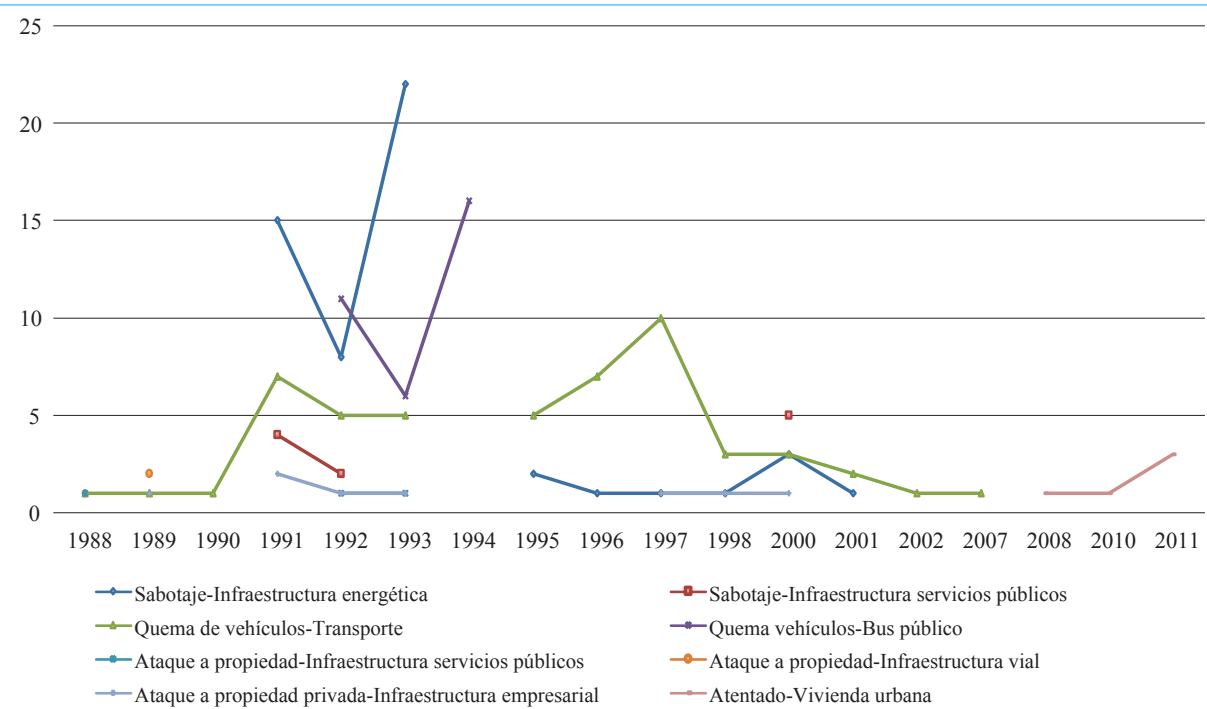

Fuente: elaboración propia, a partir de la base de datos Daños a Bienes, 1980-2012, de los Grupos Armados, del Centro de Memoria Histórica (s. f.).

10 por grupos armados no identificados, 4 por guerrilleros y 2 por la fuerza pública (figuras 5 y 6). El aumento de las masacres durante el periodo 1991-2001 coincidió con la incursión paramilitar, cuya estrategia de control social se basada en generar terror en la población civil. 
FIGURA 5. NÚMERO DE MASACRES, 1985-2012

6

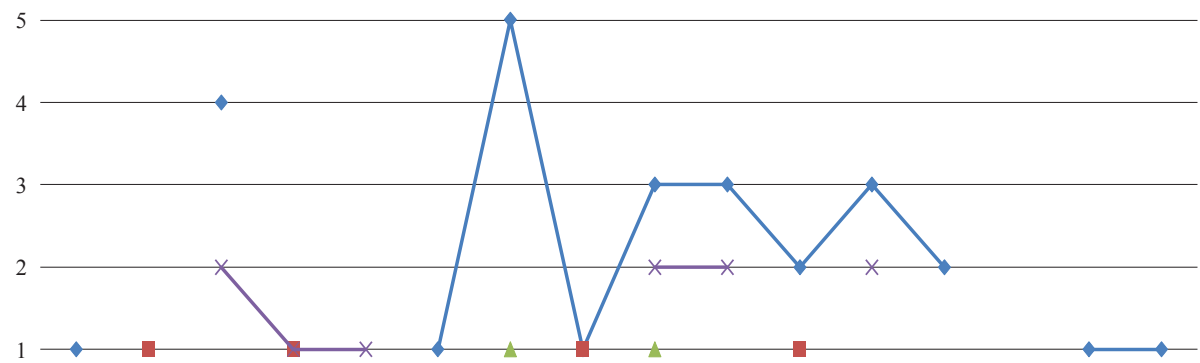

0

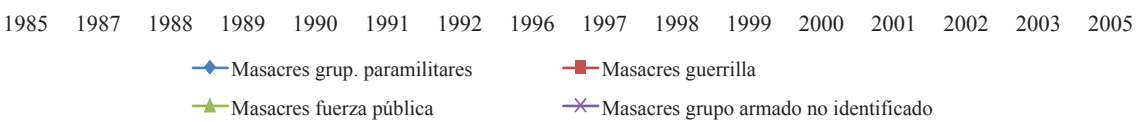

Fuente: elaboración propia, a partir de la base de datos Daños a Bienes, 1980-2012, de los Grupos Armados, del Centro de Memoria Histórica (s. f.).

FIGURA 6. VÍCTIMAS DE MASACRES, 1985-2012

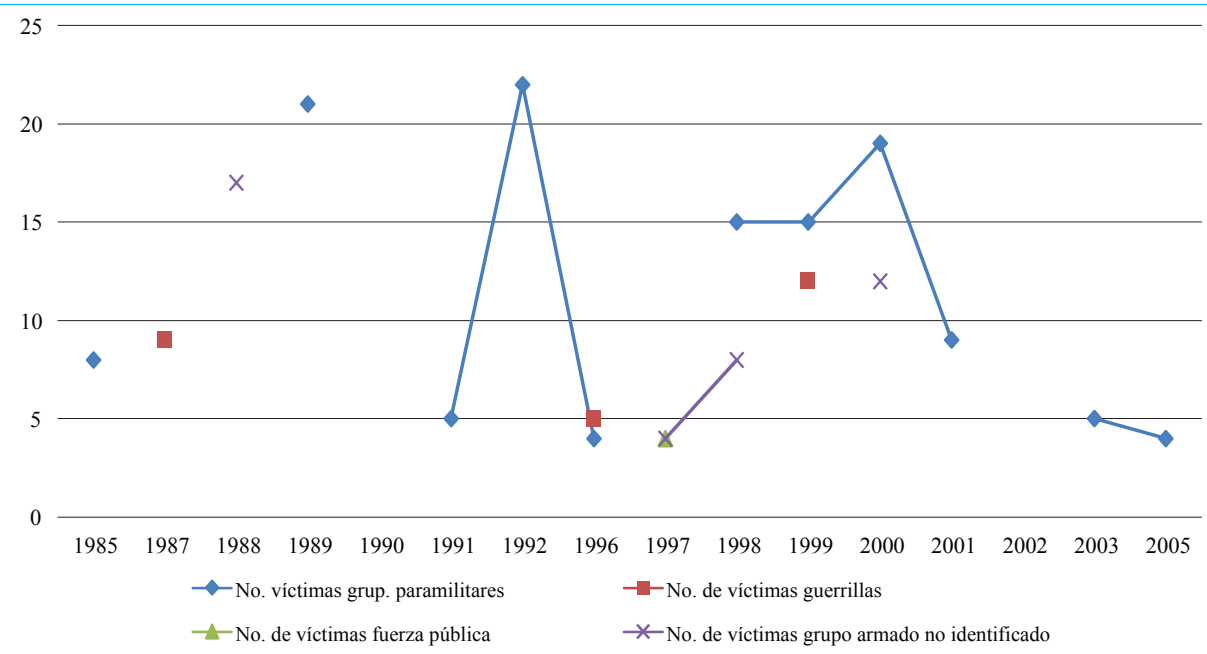

Fuente: elaboración propia, a partir de la base de datos Daños a Bienes, 1980-2012, de los Grupos Armados, del Centro de Memoria Histórica (s. f.). 


\section{LA APARICIÓN DEL PROBLEMA Y EL PROCESO DE AGENDAMIENTO DEL TEMA EN UN CONTEXTO DE VIOLENCIA}

Un día después de sucedida la masacre del 16 de mayo, organizaciones sociales del municipio como la Unión Sindical Obrera (uso) y la Coordinadora Popular emprendieron protestas en señal de rechazo al ataque paramilitar que dejó 32 víctimas. Inicialmente, 7 personas fueron asesinadas y 25 desaparecidas, por lo que en las protestas, además del rechazo a este acto violento, se exigía la intervención del Gobierno en la búsqueda de estas 25 personas, que en ese momento se consideraban con vida.

Siguiendo a Spector y Kitsuse (1977, citados por Parsons 2007), la construcción de la masacre como un tema público siguió el siguiente orden: 1) las organizaciones sociales la definieron como una situación ofensiva y publicitaron sus afirmaciones en medios de comunicación nacionales e internacionales, llegando a convertirla en un asunto de interés público, lo cual generó un efecto búmeran; 2) el Gobierno nacional reconoció la legitimidad de las organizaciones sociales que emprendieron las protestas, y decidió responder a las demandas hechas (por ejemplo, creación de la Comisión de Búsqueda de los desaparecidos); 3) el resurgimiento de las peticiones y demandas por insatisfacción a las respuestas del Estado.

En este proceso, los medios de comunicación fueron un mecanismo determinante para la posterior formulación de políticas públicas (figura 7). Prueba de ello es que antes de la masacre, entre el 1 de enero al 15 de mayo de 1998, aparecieron en la prensa 88 noticias sobre Barrancabermeja (59 en medios

FIGURA 7. RELEVANCIA DEL TEMA EN MEDIOS DE COMUNICACIÓN, FEBRERO-OCTUBRE, 1998

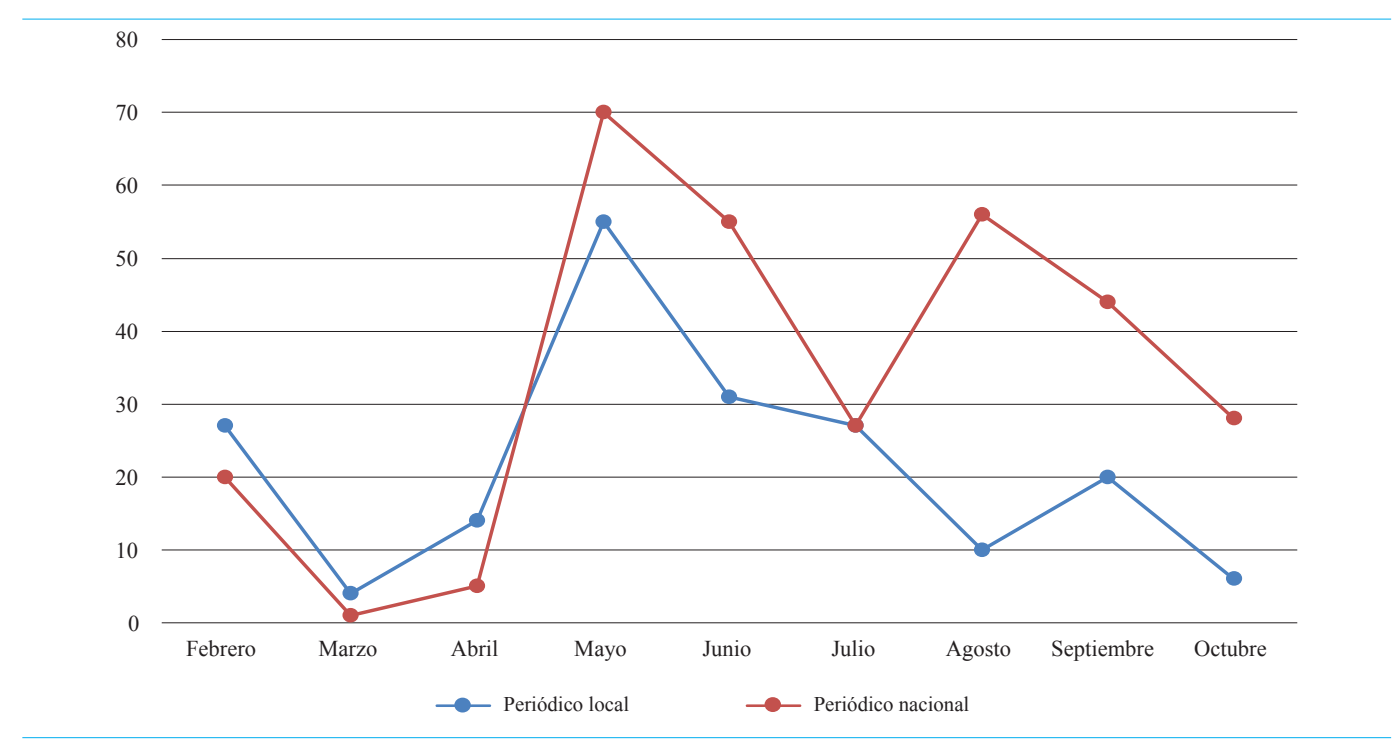

Fuente: elaboración propia, a partir del archivo de periódicos del CINEP. 
locales y 29 en medios nacionales), la mayoría sobre las protestas sindicales de la uso y atentados de guerrilleros a la población civil, mientras que después de ocurrida la masacre, es decir del 17 de mayo a octubre de 1998, se publicaron 500 noticias sobre Barrancabermeja (194 en medios locales y 306 en medios nacionales), principalmente en los meses de mayo y julio. De esta manera, el problema pasó a ser un tema de interés nacional, entrando a conformar una agenda sistémica con incidencia institucional (Elder, 1972, citado por Parsons, 2007).

Los actos violentos ocurridos en Barrancabermeja en 1998 acapararon las noticias sobre el municipio en los medios de comunicación, ya que significaron el 58 \% (288) de los registros en 1998. La masacre del 16 de mayo significó el 29\% (144) del total de registros durante el ańo, y el $50 \%$ de los registros sobre actos violentos con mayor preponderancia en el mes de mayo. Asimismo, los asesinatos representaron el $14 \%$ de los registros totales y el $25 \%$ sobre actos violentos. Por último, las amenazas a líderes de organizaciones sociales representaron el $5 \%$ del total y el $9 \%$ de los registros de actos violentos, con mayor preponderancia en los meses de junio a agosto (figuras 8 y 9).

Resulta interesante observar cómo tuvieron mayor relevancia los actos violentos que el grupo perpetrador, ya que solo el $13 \%$ del total de registros hace referencia a los grupos armados ilegales, con los paramilitares por encima de los guerrilleros, como se evidencia en la figura 8. Lo anterior, teniendo en cuenta que a los primeros se les adjudica el mayor número de actos violentos en el municipio.

Según Tarrow (1998), "la violencia es el rastro más visible de la acción colectiva, tanto

FIGURA 8. ACTOS VIOLENTOS REGISTRADOS EN PERIÓDICOS EN ENTRE FEBRERO-OCTUBRE, 1998

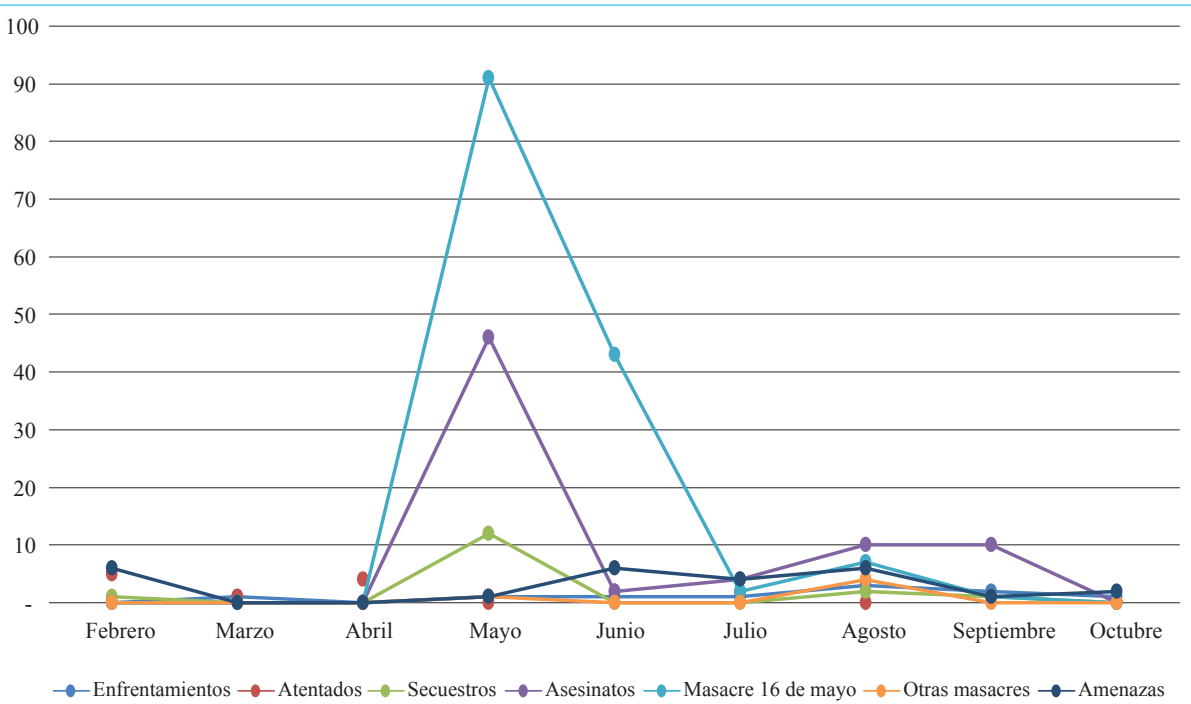

Fuente: elaboración propia, a partir del archivo de periódicos del CINEP. 
FIGURA 9. ACCIONES DE GRUPOS ARMADOS ILEGALES REGISTRADAS EN PERIÓDICOS, FEBRERO-OCTUBRE, 1998

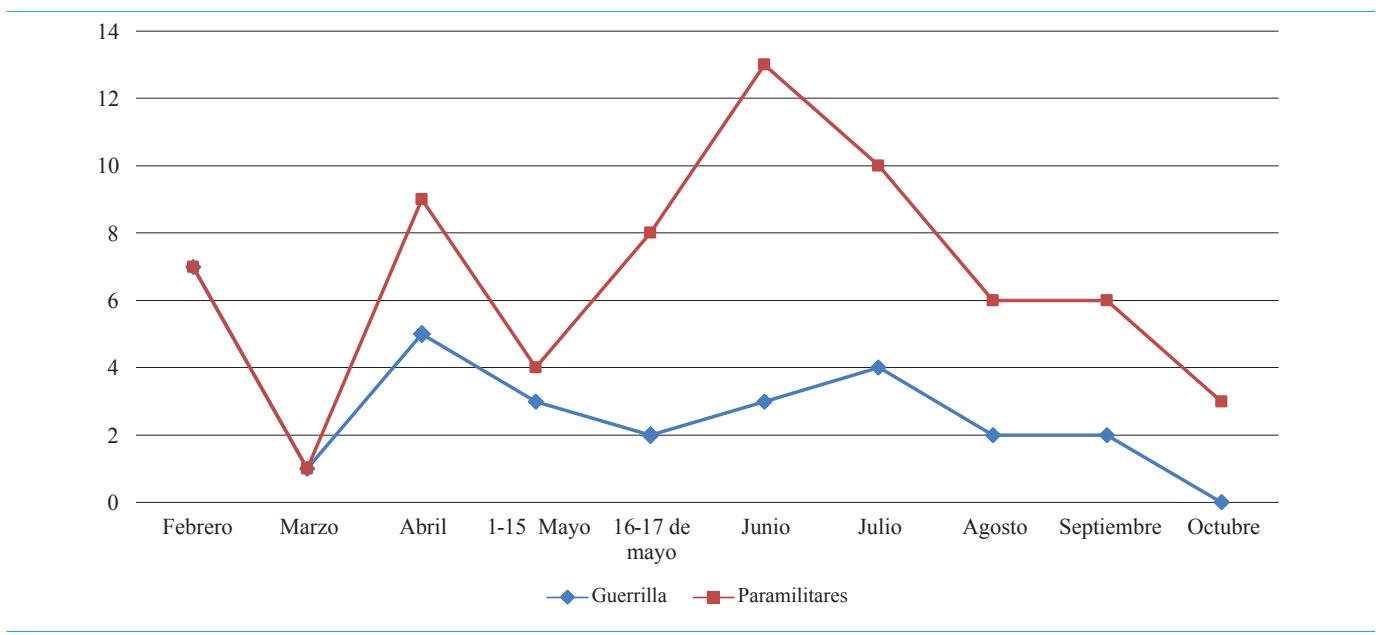

Fuente: elaboración propia a partir del archivo de periódicos del CINEP.

en la cobertura que los medios contemporáneos le ofrecen, como en el registro histórico" (p. 139), por lo cual es importante preguntar: ¿qué formas adoptan, en presencia de la violencia, acciones claves como la protesta, resistencia y movilizaciones de los actores colectivos? ¿Cómo incide la violencia sobre su proceso organizativo? Y ¿es la violencia un elemento que puede coaccionar la acción colectiva?

Las organizaciones sociales obtuvieron el $37 \%$ (184) del total de registros. La uso fue un actor clave en el proceso de convertir lo ocurrido en la masacre en un tema público. Fue la organización que más veces se registró en los periódicos, siendo nombrada $32(7 \%)$ veces, en el mes de mayo. Sin embargo, el desplazamiento colectivo de más de 8.000 personas que huían de la violencia paramilitar se convirtió en el centro de las noticias, con 80 menciones en los meses de julio a octu- bre, lo que significó el $18 \%$ de los registros sobre Barrancabermeja en la prensa (figura 10). Menor relevancia tuvieron registro en los medios de comunicación la Coordinadora Popular (11 menciones), víctimas (11 menciones), Comisión de Búsqueda de los desaparecidos (10 menciones), Iglesia (8 menciones) y la Corporación Regional para la Defensa de los Derechos Humanos (CREDHOS) (8 menciones).

A partir de lo anterior, se analizó la forma que adoptó la acción colectiva y la incidencia que tuvo la violencia en su proceso organizativo, con la descripción de los hechos ocurridos. La acción que más figuró en los periódicos nacionales un día después de la masacre fueron los paros convocados por la uso, con 30 registros, acompańados por el corte de gasolina en el municipio como mecanismo de presión al Estado. Solo en el mes de mayo se registraron 41 acciones colectivas en Barrancabermeja. A 
partir de julio tomó el protagonismo en los medios el desplazamiento colectivo de 8.000 personas, lo cual hizo mayor presión sobre el Estado, siendo determinante para que se incluyera en la agenda del Gobierno nacional el tema de la incursión paramilitar (figura 11).
Las acciones colectivas que ocurrieron después de la masacre del 16 de mayo de 1998 se agruparon de la siguiente manera: 1) los paros armados que se realizaron para exigir la búsqueda de los desaparecidos; 2) la reacción de los familiares de las víctimas

FIGURA 10. ORGANIZACIONES SOCIALES REGISTRADAS EN PERIÓDICOS, FEBRERO-OCTUBRE, 1998

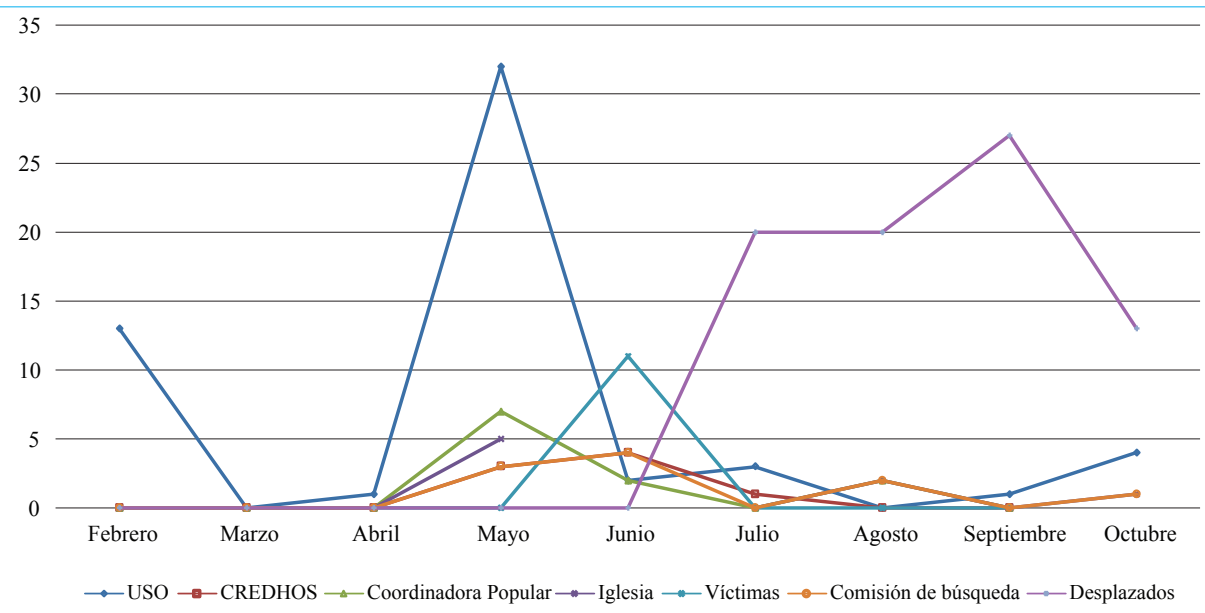

Fuente: elaboración propia, a partir del archivo de periódicos del CINEP

FIGURA 11. ACCIONES COLECTIVAS REGISTRADAS EN PERIÓDICOS, FEBRERO - OCTUBRE 2008

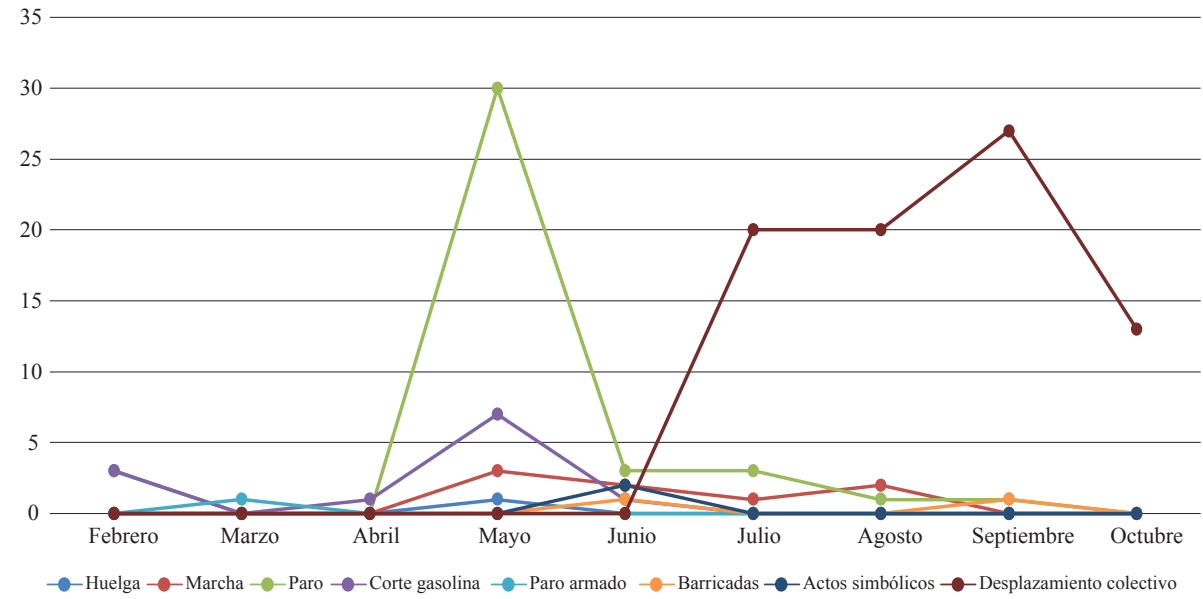

Fuente: elaboración propia, a partir del archivo de periódicos del CINEP. 
ante la noticia del asesinato de aquellos que estaban secuestrados; 3) la toma de la ciudad por 8.000 campesinos.

\section{Acciones colectivas: en búsqueda de los desaparecidos}

En mayo, la acción colectiva no se restringió a las de la uso, por el contrario, se amplió a otros sectores de la ciudad. La masacre del 16 de mayo suscitó solidaridad, pues la inminente amenaza que representó una posible nueva incursión paramilitar despertó adhesiones a las acciones emprendidas por los familiares de las víctimas, para manifestar el rechazo a estos grupos armados y pedir el regreso de sus seres queridos. A partir de ello, se pueden describir dos oleadas de acciones colectivas contenciosas, que corresponden a una coyuntura política y social en la que hay una interrelación entre las organizaciones cívicas, los grupos armados ilegales y el Estado.

La primera oleada se refiere al rechazo del ingreso de los grupos paramilitares en el municipio y la violencia generada por estos. En esta participaron tanto organizaciones cívicas como guerrilleros con actos ilegales como la quema de buses, aprovechando la coyuntura para visibilizarse y ejercer presión sobre el Gobierno.

La segunda oleada se dio como respuesta al asesinato de las 25 personas secuestradas, aún cuando las Autodefensas de Santander y Sur del César (AUSAC) se habían comprometido a mantenerlas con vida. Esta oleada detonó cuando les pidieron a las madres que enviaran fotos de sus familiares desaparecidos para entregar pruebas de supervivencia (El Espectador, 1998a). El 30 de mayo de 1998 las AUSAC se adjudicaron la autoría de la masacre del 16 de mayo y anunciaron que tenían retenidas a 25 y no a 34 personas como se decía, y que los asesinados en el recorrido de la masacre fueron 7 , además dijeron que estarían entregando pruebas de supervivencia (El Nuevo Siglo, 1998, citado en Barrios, 2012).

Por consiguiente, las organizaciones sociales construyeron una agenda sistémica alrededor de la masacre del 16 de mayo, y definieron las temáticas que merecían la atención de las instituciones públicas por su importancia social. En este punto fue fundamental el papel de los medios de comunicación que consideraron darle relevancia al tema. Además, ayudaron a delinear el contexto e influyeron en la agenda de las instituciones públicas. Este proceso se dio de la siguiente manera: ocurrió la masacre del 16 de mayo; los medios nacionales e internacionales tomaron la historia; el incidente se tomó como ejemplo de un problema social más grande, como es la expansión del paramilitarismo en el país; como resultado se generó pánico e indignación ante la oleada de violencia, ante lo cual se desarrollaron acciones colectivas que tenían como objetivo lograr la intervención del Estado (Parsons, 2007).

\section{Desplazamiento colectivo}

En julio, la acción colectiva fue impulsada principalmente por la organización campesina del Magdalena Medio. A partir de este mes llegaron a la ciudad grupos de campesinos de diferentes municipios de la región y se instalaron en algunas instituciones 
educativas de la ciudad y en la Defensoría del Pueblo, argumentando la falta de garantías para permanecer en su tierra. Este desplazamiento de alrededor 8.000 campesinos hacia Barrancabermeja y otras cabeceras municipales se denominó "éxodo campesino", y tuvo como principal motivo la presión paramilitar sobre las comunidades rurales de la región.

Entre las acciones colectivas desarrolladas por los campesinos están el saqueo de víveres, el cierre de las principales vías de la ciudad, marchas, barricadas y paros en la producción petrolera. Sus principales demandas eran: garantías para volver y permanecer en sus tierras; inversión social en las zonas rurales de la región; declaración por parte del Estado de su responsabilidad en la conformación y financiación de los grupos paramilitares, así como el desmonte de los mismos; eliminación del fuero penal militar; tipificación penal de la desaparición forzada; conformación de un tribunal penal internacional para juzgar los delitos de lesa humanidad cometidos en el Magdalena Medio; estudios por parte del Congreso del proyecto de Ley de Hidrocarburos presentado por la uso; discusión del Código Minero con las comunidades afectadas, y reubicación de las bases militares asentadas en medio de la población civil (El Espectador, 1998b).

La llegada de los campesinos a Barrancabermeja significó el fortalecimiento de la acción colectiva contenciosa en contra de la presencia de los paramilitares en su territorio, y demostró la resistencia frente la presión y las amenazas de estos. Los campesinos fueron estigmatizados como colaboradores de la guerrilla, incluso por el mismo Gobierno, sin embargo mantuvieron, al igual que las organi- zaciones cívicas presentes en Barrancabermeja, el interés por incidir en políticas de seguridad y convivencia ciudadana.

El gran número de desplazados que llegó a Barrancabermeja demostró que el objetivo de los grupos paramilitares era desarticular el tejido social democrático y atacar a la población, supuestamente colaboradora de la guerrilla, como parte de una estrategia de control de la región del Magdalena Medio.

\section{ACCIÓN COLECTIVA Y DECISIONES DE POLÍTICA PÚBLICA}

La masacre del 16 de mayo reflejó una problemática social en la región del Magdalena Medio que adquirió interés público a través de la movilización de las organizaciones sociales de la zona; no obstante, la influencia que se logra sobre la formulación y ejecución de políticas públicas mediante la acción colectiva requiere el análisis a partir de la respuesta del sistema político a sus demandas. Dicho análisis se basa en el éxito procedimental, entendido como el proceso mediante el cual se abren los canales de participación y se reconoce legítimamente a los grupos y organizaciones sociales, y en el éxito sustancial proactivo que se evalúa en tres fases: 1) acceso y posicionamiento del tema en la agenda pública, 2) adopción del contenido de las propuestas, 3) implementación de las políticas adoptadas.

\section{Acceso y posicionamiento del tema en la agenda pública}

De acuerdo con el seguimiento a las noticias que fueron emitidas en la prensa sobre 
las decisiones políticas tomadas alrededor de la masacre, en términos comparativos se evidencia un alto número de publicaciones en la prensa nacional, por encima de los niveles departamental y local para los meses de mayo, junio, julio y agosto, en orden descendente. Dicho esto, se podría afirmar que las decisiones a las que se hace referencia se relacionan con una atención inmediata por parte del ente gubernamental y otros organismos ante la crisis humanitaria que se generó por las acciones violentas de los paramilitares; sin embargo, no obedecen necesariamente a la incorporación de esta problemática en la agenda pública.

En los periódicos aparecen 56 menciones sobre decisiones políticas alrededor de las movilizaciones en Barrancabermeja, con mayor prevalencia en los meses en los que ocurrió la masacre y el desplazamiento colectivo de campesinos. De estas menciones, 40 correspondieron al ámbito nacional, es decir, el $71 \%$ de los registros; 14 (25\%) al ámbito local y $2(4 \%)$ al departamental. Así mismo, se encontraron 21 registros de los acuerdos y negociaciones entre el Gobierno y las organizaciones sociales, la mayoría de ellos en relación con mesas de diálogo de los desplazados (figuras 12 y 13 ).

\section{Adopción del contenido de las propuestas}

La política pública es una práctica y un proceso social orientado a tramitar las demandas de las organizaciones sociales. En este sentido, luego del 16 de mayo se tomaron acciones inmediatas, como la creación de un Comité de Búsqueda y la Comisión de la Verdad, y de un puesto de Policía del Magdalena Medio.

Entendiendo que el inicio de una política pública se encuentra en una situación que una sociedad y un Gobierno definen como un problema prioritario, se evidencia que tanto en la administración municipal como en el Gobierno nacional el tema del orden público de Barrancabermeja comenzó a figurar en la formación de la agenda pública a partir, principalmente, de la visibilización que tuvo la masacre del 16 de mayo.

No obstante, el surgimiento de un problema público va más allá de un tema que toma relevancia, puesto que no todos los problemas se pueden convertir en públicos y no todos los problemas públicos adquieren una forma concreta que se traduzca en una política pública. No en vano, la agenda pública difiere sustancialmente de la gubernamental, pues mientras en la primera caben todas las cuestiones que una comunidad política acepta como merecedora de atención pública y, además, como asuntos de jurisdicción gubernamental; en la segunda están los asuntos que los tomadores de decisiones aceptan explícitamente para su consideración seria y activa.

A partir de la primera oleada de acción colectiva, que duró cinco días (del 18 al 23 de mayo), y que involucró huelga de trabajadores, movilizaciones, bloqueos y corte de la gasolina, el entonces presidente de la república Ernesto Samper se desplazó a Barrancabermeja el 29 de mayo y conformó un Comité de Búsqueda de los desaparecidos, a su vez, anunció la creación de un departamento de Policía Nacional en el municipio (El Espectador, 1998c). Además, adquirió el 
FIGURA 12. DECISIONES POLÍTICAS REGISTRADAS EN PERIÓDICOS, FEBRERO-OCTUBRE, 1998

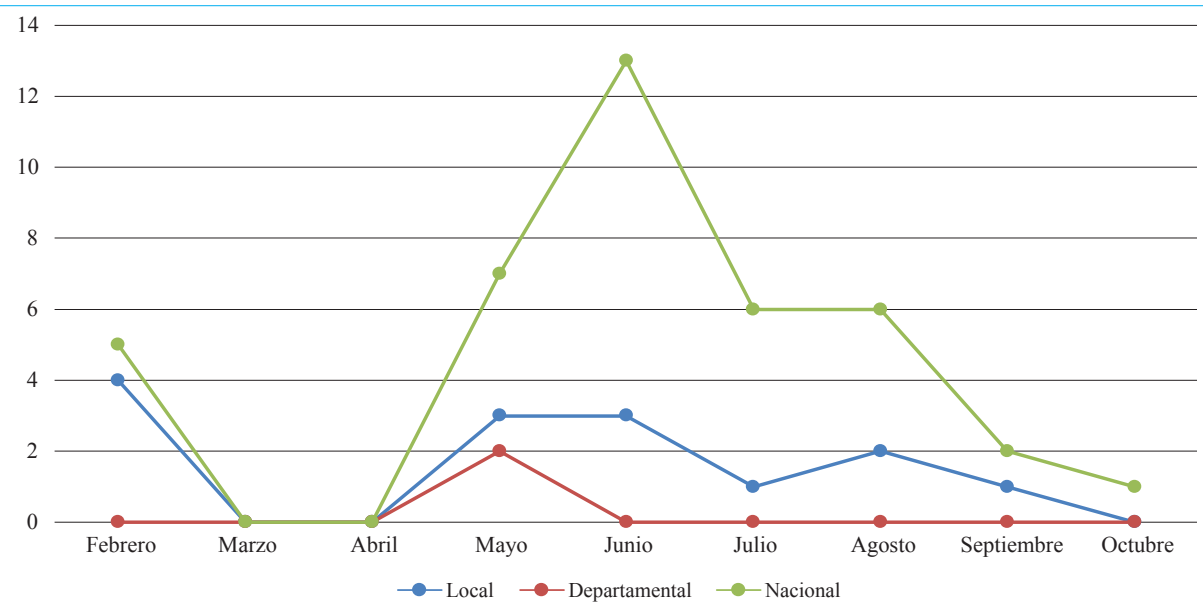

Fuente: elaboración propia, a partir del archivo de periódicos del CINEP.

FIGURA 13. ACUERDOS Y NEGOCIACIONES REGISTRADOS EN PERIÓDICOS, FEBRERO-OCTUBRE, 1998

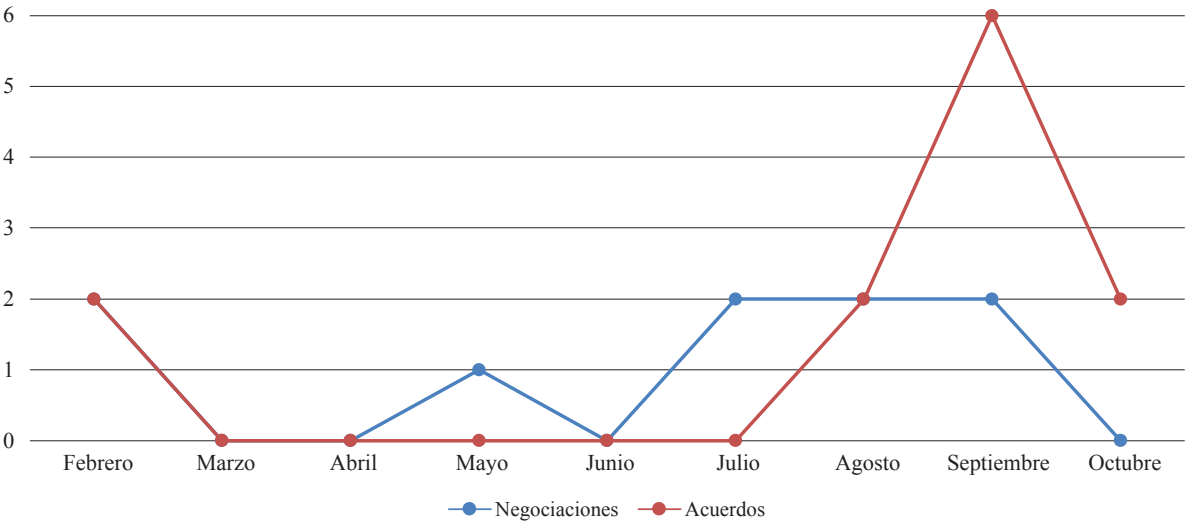

Fuente: elaboración propia, a partir del archivo de periódicos del CINEP.

compromiso de abrir procesos de investigación exhaustiva de los hechos, constitución por parte de la Fiscalía General de la Nación de una comisión extraordinaria de nivel nacional para investigar, sancionar y castigar a los responsables, búsqueda y devolución de los desaparecidos forzados, establecimiento de un plan de seguridad ciudadana y garantía, entre otros. 
Las respuestas en el ámbito local iban más orientadas a crear los mecanismos institucionales y legales para encontrar a los desaparecidos y culpables de los hechos. Así mismo, a generar credibilidad en el gobierno local, mediante pronunciamientos públicos. Sin embargo, estas acciones fueron respuestas cortoplacistas a una situación específica. Esto con excepción de la propuesta de crear un Plan de Desarrollo Económico para el sector nor y suroriental, ya que este tipo de acciones, por un lado, reconocían la existencia de una segregación socioespacial que generaba exclusión económica, y, por otro lado, proponía soluciones a largo plazo que podían ayudar a superar los problemas de fondo.

Por su parte, las decisiones en el ámbito nacional iban más orientadas a crear organismos institucionales de orden nacional, que permitieran tener presencia y acompańamiento estatal en temas de seguridad. En este sentido, centralizó la seguridad, en lugar de fortalecer el gobierno local.

TABLA 1. PRIMERA OLEADA DE ACCIÓN COLECTIVA: PARO CÍVICO

\begin{tabular}{|c|c|c|}
\hline Demanda & Respuesta & Resultado \\
\hline \multirow{15}{*}{$\begin{array}{l}\text { Conocer } \\
\text { la autoría } \\
\text { de la ma- } \\
\text { sacre y la } \\
\text { ubicación } \\
\text { de las } 25 \\
\text { personas } \\
\text { desapa- } \\
\text { recidas }\end{array}$} & \multicolumn{2}{|l|}{ Ámbito local } \\
\hline & Una Asamblea Popular en la que se llegó a los siguientes acuerdos (Vanguardia Liberal, 1998 a): & \multirow{9}{*}{$\begin{array}{l}\text { Éxito sus- } \\
\text { tancial } \\
\text { proactivo }\end{array}$} \\
\hline & 1. Apertura del proceso de investigación exhaustiva, conformada por miembros de la Fiscalía. & \\
\hline & $\begin{array}{l}\text { 2. Búsqueda de los desaparecidos forzados, liderada por la Defensoría Nacional, apoyada por } \\
\text { la Consejería Presidencial para la Paz, la oficina del zar antisecuestro, contará con el apoyo } \\
\text { permanente de la Cruz Roja Internacional. }\end{array}$ & \\
\hline & 3. Establecimiento de un plan de seguridad ciudadana y garantía de la población civil de Barranca. & \\
\hline & $\begin{array}{l}\text { 4. Crear una oficina delegada de orden nacional conformada por la Fiscalía y la Procuraduría } \\
\text { General. }\end{array}$ & \\
\hline & 5. Pronunciamiento público de los hechos ocurridos. & \\
\hline & $\begin{array}{l}\text { 6. Elaboración de un Plan de Desarrollo económico en el sector nor y suroriental, que se llevará } \\
\text { a cabo el } 15 \text { de junio de } 1998 .\end{array}$ & \\
\hline & $\begin{array}{l}\text { 7. Fortalecimiento del poder público local representado en la administración y el Concejo } \\
\text { municipal. }\end{array}$ & \\
\hline & 8. Seguimiento de los compromisos adquiridos. & \\
\hline & \multicolumn{2}{|l|}{ Ámbito nacional } \\
\hline & Consejero Presidencial. & \multirow{4}{*}{$\begin{array}{l}\text { Éxito sus- } \\
\text { tancial } \\
\text { proactivo }\end{array}$} \\
\hline & Comisión de la Verdad. & \\
\hline & $\begin{array}{l}\text { Plan con la Red de Solidaridad Social de Apoyo a los familiares de las víctimas, con una inver- } \\
\text { sión de } 6 \text { mil millones de pesos. }\end{array}$ & \\
\hline & Departamento de Policía del Magdalena Medio. & \\
\hline
\end{tabular}


Por su parte, las decisiones en el ámbito nacional iban más orientadas a crear organismos institucionales de orden nacional, que permitieran tener presencia y acompañamiento estatal en temas de seguridad. Además, el comportamiento de Gobierno nacional estuvo encaminado a empoderar al gobierno local en el liderazgo de la seguridad local e incluso regional.
La segunda oleada de acción colectiva se desató el 2 de junio, cuando el consejero presidencial para la paz, José Noé Ríos, se comprometió a entregar pruebas de supervivencia de los desaparecidos (Vanguardia Liberal, 1998 b). Después de haber pedido las fotos de las víctimas, el 4 de junio de 1998 las AUSAC anunciaron públicamente que los secuestrados habían sido asesinados y sus cuer-

TABLA 2. SEGUNDA OLEADA DE ACCIÓN COLECTIVA: REACCIÓN

\begin{tabular}{|c|c|c|}
\hline Demanda & Respuesta & Resultado \\
\hline \multirow{16}{*}{$\begin{array}{l}\text { Expresión } \\
\text { de descon- } \\
\text { tento con } \\
\text { el Gobier- } \\
\text { no ante la } \\
\text { noticia del } \\
\text { asesinato } \\
\text { de los des- } \\
\text { aparecidos }\end{array}$} & \multicolumn{2}{|l|}{ Ámbito local } \\
\hline & Manifestaciones de repudio y dolor. & \multirow{2}{*}{$\begin{array}{l}\text { Éxito } \\
\text { procedi- } \\
\text { mental }\end{array}$} \\
\hline & $\begin{array}{l}\text { Encuentro en Bogotá para revisar compromisos con el Gobierno nacional (Vanguardia } \\
\text { Liberal, } 1998 \text { c, p. 4c). }\end{array}$ & \\
\hline & \multicolumn{2}{|l|}{ Ámbito nacional. } \\
\hline & $\begin{array}{l}\text { Promesa de activación de Comisión de Investigación y Comisión de la Verdad (Vanguardia } \\
\text { Liberal, } 1998 \text { d, p. 3c). }\end{array}$ & \\
\hline & $\begin{array}{l}\text { Creación de una nueva comisión de la verdad, conformada por: Defensoría del Pueblo, alto } \\
\text { comisionado para la paz y el vicefiscal (El Colombiano, 1998a, p. 13A). }\end{array}$ & \\
\hline & $\begin{array}{l}\text { De la reunión del alcalde con el Gobierno nacional, el } 16 \text { de junio se obtuvieron los siguien- } \\
\text { tes acuerdos (El Colombiano, 1998b): }\end{array}$ & \\
\hline & $\begin{array}{l}\text { 1. Red de solidaridad apoyará a los familiares de las víctimas de la masacre, con una póliza } \\
\text { de } 10 \text { millones de pesos por hogar. }\end{array}$ & \\
\hline & $\begin{array}{l}\text { 2. El Ministerio de Salud se comprometió a aumentar la cobertura del régimen subsidiado y } \\
\text { contribuir con equipo médicos. }\end{array}$ & o sus- \\
\hline & 3. Continuar con el Programa de Desarrollo y Paz para el Magdalena Medio. & \\
\hline & $\begin{array}{l}\text { 4. Contribuir con el propósito de apoyo para los maestros y realizar aportes para construir } \\
\text { establecimientos educativos. }\end{array}$ & \\
\hline & $\begin{array}{l}\text { 5. Apoyar con un aporte de } 900 \text { millones de pesos la construcción de un acueducto para } \\
\text { Barrancabermeja. }\end{array}$ & \\
\hline & 6. Que el Instituto Nacional de Vías (INVÍAS) continúe los estudios de vía campo 23. & \\
\hline & 7. Construcción de doble calzada para el acceso al Puerto Petrolero. & \\
\hline & 8. El SENA y Ecopetrol apoyarán distintos programas de capacitación laboral. & \\
\hline & $\begin{array}{l}\text { 9. Planeación Nacional destinará recursos de un programa nuevo de convivencia, después } \\
\text { de que se presenten los respectivos proyectos. }\end{array}$ & \\
\hline
\end{tabular}


pos incinerados, ajusticiados por pertenecer a las guerrillas del ELN y EPL.

En el ámbito local, el éxito de la acción colectiva fue más procedimental, ya que se lograron abrir canales de participación con el Gobierno nacional, buscando garantizar el cumplimiento de los compromisos adquiridos en mayo. Con ello se logró la reafirmación del Gobierno de la creación de la Comisión de la Verdad y el Comité de Desaparecidos. Los canales de participación fueron aprovechados por el gobierno local para obtener apoyo en otras políticas sociales como salud, educación e infraestructura (tabla 2).

Sin embargo, la única decisión que respondió al inconformismo de la comunidad fue el apoyo económico a los familiares de los 25 desaparecidos, mediante una póliza de 10 millones de pesos. En este punto, llama la atención que la problemática social se estaba limitando al esclarecimiento de los hechos, búsqueda de culpables y a la reparación económica, mas no a combatir a los paramilitares y restablecer el orden y la seguridad.

A partir de las acciones colectivas que se desataron con el desplazamiento campesino, el 22 de agosto de 1998 inició la mesa de negociación para hablar sobre las condiciones para el regreso de los desplazados a sus tierras. La mesa quedó conformada por la Coordinadora Popular de Barrancabermeja, la uso, los delegados de los desplazados, el Ministerio del Interior, la Procuraduría, la Fiscalía, la Defensoría del Pueblo y el Ministerio de Minas y Energía.

1 Creadas para que los campesinos se autodefendieran.
El 30 de julio, ocho días después de la llegada al municipio de los campesinos, y a pocos días del cambio de Gobierno, se había logrado que este se sentará a negociar, sin embargo, esto se pospuso hasta la posesión de presidente electo Andrés Pastrana, reprogramada para el 7 de agosto (El Espectador, 1998 d, p. 11A).

El 28 de agosto, en acuerdo con los desplazados, el Gobierno se comprometió a desmontar las Cooperativas de Vigilancia y Seguridad Privadas (Convivir) ${ }^{1}$ que irrespetaban los derechos y las libertades de las comunidades, también a respetar y hacer respetar los derechos humanos (El Espectador, 1998b, p. 11A).

Durante 44 días, los desplazados y el Gobierno nacional se sentaron en la mesa denominada "El Magdalena Medio permanente por la paz", que se realizó en la Biblioteca Galvis Galvis de Barrancabermeja. Finalmente, el 5 de octubre, después de 104 días de estar en Barranca y 45 de negociaciones, los campesinos retornaron a sus tierras (El Espectador, 1998e, p. 4A).

La presencia de más de 8.000 campesinos provenientes de los municipios del Magdalena Medio y su permanencia por más de 104 días, se volvió un tema de carácter nacional, en el que el gobierno local tuvo una participación mínima, ya que incluso esto salía de sus competencias como ente territorial. Finalmente, el Estado se comprometió a establecer una política contra los paramilitares y el castigo a los miembros de la fuerza pública aliados (tabla 3). 
TABLA 3. DESPLAZAMIENTO COLECTIVO DE LOS CAMPESINOS A BARRANCABERMEJA

\begin{tabular}{|c|c|c|}
\hline Demandas & Respuesta & Resultado \\
\hline \multicolumn{3}{|c|}{ Ámbito nacional } \\
\hline $\begin{array}{l}\text { Que el Estado se } \\
\text { haga responsa- } \\
\text { ble de la crea- } \\
\text { ción de grupos } \\
\text { de justicia } \\
\text { privada como } \\
\text { las Convivir }\end{array}$ & Un proyecto que defina la política estatal contra los grupos paramilitares. & \multirow{8}{*}{$\begin{array}{l}\text { Éxito } \\
\text { sustancial } \\
\text { proactivo }\end{array}$} \\
\hline $\begin{array}{l}\text { El desmonte } \\
\text { de unidades de } \\
\text { inteligencia y } \\
\text { bases militares } \\
\text { donde la co- } \\
\text { munidad está } \\
\text { asentada }\end{array}$ & $\begin{array}{l}\text { El Ministerio de Defensa, las fuerzas militares, la Policía y el DAS, tendrán que mos- } \\
\text { trar resultados contra los paramilitares. }\end{array}$ & \\
\hline \multirow{5}{*}{$\begin{array}{l}\text { La destitución y } \\
\text { el castigo de los } \\
\text { comandantes } \\
\text { militares que } \\
\text { tengan vínculos } \\
\text { con la guerrilla }\end{array}$} & $\begin{array}{l}\text { Creación del bloque de búsqueda contra el paramilitarismo en el Magdalena Medio, } \\
\text { con accionar en Antioquia, Boyacá, Bolívar, Cesar, Santander y Sucre. }\end{array}$ & \\
\hline & $\begin{array}{l}\text { La Procuraduría General sancionó a cinco militares de la Fuerza Pública que partici- } \\
\text { paron en la masacre del } 16 \text { de mayo (El Espectador, 1998). }\end{array}$ & \\
\hline & $\begin{array}{l}\text { Gestionar recursos para la formulación del Plan de Desarrollo y Protección Integral } \\
\text { de Derechos Humanos del Magdalena Medio. }\end{array}$ & \\
\hline & $\begin{array}{l}\text { Entrega de un subsidio de retorno de } 280.000 \text { pesos mensuales a cada una de las } \\
1.700 \text { familias. }\end{array}$ & \\
\hline & $\begin{array}{l}\text { El Ministerio del Interior y el Incora se comprometieron a darles salida temporal } \\
\text { o definitiva a las familias que por motivos de seguridad no puedan retornar a sus } \\
\text { sitios de origen. }\end{array}$ & \\
\hline Estatuto Minero & & \\
\hline
\end{tabular}

En consecuencia, el desplazamiento colectivo fue clave para que se reforzara el mensaje de que los problemas de seguridad en el municipio eran un tema de interés nacional, y de que se estaba permitiendo que el terror paramilitar avanzara, incluso con alianza de la fuerza pública. Por ello, las demandas se centraron en el desmonte del paramilitarismo y la destitución de los comandantes de la fuerza pública que hacían parte de la estrategia de control social.

\section{Implementación de las políticas públicas de seguridad y convivencia ciudadana}

La implementación de las decisiones políticas es una etapa fundamental en el ciclo de políticas públicas porque es cuando las promesas se convierten en hechos, como señala Wildavsky Pressman (1998, p. 327, citado por Roth, 2002) “La política de implementación es la determinante definitiva del 
resultado", en esta etapa se generan actos, a partir de un marco normativo definido, para su implementación. Ingram (citado por Roth, 2002) propone tener en cuenta el contexto, los costos de información y negociación, la estructura reglamentaria utilizada y la capacidad administrativa.

De esta manera, se buscó identificar las políticas públicas locales y nacionales en el periodo 1998-2014 orientadas a fortalecer la seguridad de los ciudadanos frente a cualquier tipo de delitos que afecten su dignidad y las orientadas a fomentar la convivencia a través de la promoción de una cultura ciudadana basada en el respeto a la Ley. Estas políticas se analizaron desde los enfoque de buen gobierno y clásico de administración racional (top dowm).

\section{Enfoque de buen gobierno}

Las medidas de política pública en el ámbito local más relevantes desde 1998 al presente año han sido la constitución de Concejo Municipal de Paz (Acuerdo 016 de 1998), el Comité Intersectorial por la Defensa de la Vida (Decreto 1747 de 2002), la construcción del Centro de Convivencia Ciudadana con trascendencia en el ámbito nacional (Ley 812 de 2003, capítulo II, literal A), la asignación de un Asesor de Paz y Convivencia (Decreto 061 de 2006) y la declaración del 16 de mayo como el "Día municipal de la conmemoración de las víctimas de las violaciones de los derechos humanos y el derecho internacional humanitario" (Acuerdo 011 de 2009).

Estas políticas se caracterizaron por la participación de un conjunto de instituciones y agentes procedentes del Gobierno y fuera de él, en el que fueron claves las organizaciones sociales protagonistas de las acciones colectivas en el periodo, y el reconocimiento de la interdependencia entre las instituciones que intervienen en la acción pública (Roth, 2002). Desde el enfoque de buen gobierno se considera que las políticas públicas se construyen a partir de la decisión de los entes gubernamentales de crear escenarios y estrategias de participación como resultado de la interacción de actores sociales y políticos reconocidos, para aumentar las posibilidades de gestión de una institución.

\section{Enfoque clásico de la administración racional}

Un alto número de las políticas gubernamentales implementadas en el país son definidas desde los programas y planes de Gobierno desarrollados desde una perspectiva top down, que considera que la administración pública tiene la tarea de transformar los objetivos en medios, sustituir la política por la técnica y los conflictos por las racionalidades. Esto supone que son los gobernantes y sus asesores los que tienen los mecanismos para dar respuesta a lo que consideran son las problemáticas sociales más relevantes. En este punto se describen las políticas de seguridad y convivencia ciudadana consignadas en los planes de desarrollo municipales (PDM) en el periodo 2001-2014.

El panorama de violencia que vivía el municipio como consecuencia de la incursión paramilitar en 1998, sirvió de justificación para la campaña política a la alcaldía de Julio César Ardila (2001-2003), quien se tomó la 
paz como bandera política y logró posicionar su programa de gobierno "Barrancabermeja, una oportunidad para la Paz". Es de resaltar que en su PDM se hizo alusión a la existencia de una cultura del conflicto que significaba la destrucción del liderazgo local, por lo cual propuso en contraposición consolidar una cultura de la participación. Este PDM se caracterizó por dar relevancia a la atención de población víctima de la violencia y la participación ciudadana, pero además a la investigación, la planeación a largo plazo, el fortalecimiento de los valores y la presencia estatal y privada.

El PDM del gobierno de Edgar Cote Garavino (2004-2007) se caracterizó por empoderar a la ciudadanía en la promoción de los derechos humanos y la solución de conflictos, así como por promover la participación ciudadana. En este caso, la seguridad ciudadana se fortaleció principalmente desde la inserción de recursos. Llama la atención la inclusión del patrimonio y la incentivación del sentido de pertenencia como un sentido de convivencia más que de cultura.

El PDM del gobierno de Carlos Contreras (2008-2011) tuvo un fuerte componente participativo, en el que fue clara la interdependencia con las organizaciones sociales, y en el que solo se hizo mención de la importancia de la atención a los desplazados, los derechos humanos y la legalidad, pero no fueron claros los mecanismos mediante los cuales se esperaba llevar a cabo estas acciones, metas e indicadores.

Por último, Elkin Bueno Altahona (2012-2015), en su PDM "En Barrancabermeja el futuro se construye hoy", propuso como eje estructurante la conformación de una "Barrancabermeja culta, segura, participativa y pacífica", con el objetivo de "garantizar la seguridad ciudadana, el orden público y la atención integral, promoviendo la convivencia ciudadana y la no vulneración de los derechos fundamentales" (p. 257), la cual parte del reconocimiento de la ruptura del tejido social por el conflicto armado.

Las políticas de seguridad y convivencia ciudadana tienen un componente fuerte de participación desde las perspectivas planteadas. Desde el enfoque de buen gobierno las organizaciones sociales logran hacer parte de los espacios de toma de decisiones, tanto en el ámbito local como nacional, en el que es claro el reconocimiento de las organizaciones sociales como actores influyentes y la importancia de su participación en el desarrollo de las políticas.

Desde el enfoque clásico de la administración racional se busca fortalecer los mecanismos de participación ciudadana, siendo fundamental la capacitación de los líderes sociales, incluso más que la inversión en seguridad ciudadana que queda supeditada a la inversión en infraestructura. Estos líderes se ven como aliados del Estado que pueden contribuir a la consolidación de la convivencia ciudadana, a la promoción de los derechos humanos y a ser agentes en la solución de conflictos. Estas políticas se caracterizaron por costes de negociación e información bajos, ya que tenían objetivos claros y dejaban a los administradores públicos una autonomía para determinar los procedimientos requeridos para su implementación, sin embargo, los factores críticos se encuentran en los cambios que se produjeron en el contexto social (Roth, 2002). 


\section{CONCLUSIONES}

En 1998, la masacre del 16 de mayo se volvió un tema de interés nacional ya que contribuyó a visibilizar el accionar de los grupos paramilitares (masacres, asesinatos selectivos, desaparición forzada), y su estrategia para tomar el control territorial del Magdalena Medio. La mayoría de las demandas tramitadas por las organizaciones sociales iban orientadas a la búsqueda de las personas desaparecidas y a exigir el compromiso del Gobierno de combatir a los grupos paramilitares.

Esta masacre marcó un hito histórico que en 1998 desató dos oleadas de acciones colectivas que contribuyeron a posicionar el problema como un tema de interés público. Entre las acciones colectivas emprendidas estaban el paro cívico convocado por la uso, las protestas por el fraude en la entrega de pruebas de supervivencia y las que se desencadenaron por las amenazas contra líderes sociales. Sin embargo, fue el éxodo de 8.000 campesinos el que dimensionó la magnitud del problema y ocupó la agenda del expresidente Andrés Pastrana cuando recién se posicionó en su cargo.

La gran capacidad de presión de las organizaciones sociales significó un problema para el Estado, por las pérdidas económicas que ocasionaban las protestas lideradas por la uso, en especial para la refinería de Barrancabermeja. Estas protestas se caracterizaron por la organización en red y acción colectiva, que se explica desde las macro y micromotivaciones, en las que hay una gran orientación al altruismo. La participación de la uso es un ejemplo de ello, teniendo en cuenta que la situación de violencia en el municipio, más que una cuestión laboral, era social. Esta percepción ha cambiado con el tiempo, ya que el sindicato obrero se viene ocupando más de apoyar las demandas laborales propias de la industria petrolera.

El proceso vivido en Barrancabermeja en 1998 permite afirmar que al ser desarrollada la acción colectiva en medio del conflicto armado, este es a la vez su motivador y limitante. Motivador porque las acciones contra la población civil, urbana y rural generaron demandas por parte de las organizaciones sociales en el sentido de exigir que el Estado garantizará el respeto de los derechos humanos; limitante, porque al ser realizadas dichas demandas en un contexto de conflicto armado, las organizaciones sociales se convirtieron en blanco de amenazas por parte de los grupos paramilitares y estigmatización por parte del Estado al señalar la "infiltración” de la guerrilla. Así mismo, la guerrilla aprovechó la coyuntura de descontento social para demostrar su control territorial, mediante acciones bélicas o atentados a la infraestructura.

En la figura 8, "Actos violentos registrados en periódicos en enero-octubre, 1998", y en la figura 9, "Acciones de grupos armados ilegales registradas en periódicos, febrerooctubre, 1998", se ve reflejada la relevancia que adquirieron los problemas de violencia del municipio en la prensa local y nacional.

Por lo expuesto anteriormente, se halló que las acciones colectivas de las organizaciones, en el periodo 1998-2001, incidieron en la definición de la agenda pública, y posterior formulación e implementación de políticas de seguridad y convivencia ciudadana en el municipio, como reacción a la situación de 
conflicto armado que se vivió en la época. Las organizaciones sociales recibieron respuesta por parte del Gobierno nacional y local, ya que lograron, primero, participar en las decisiones políticas más representativas y, segundo, que el Gobierno incluyera dentro de los planes de desarrollo, en el ámbito local y nacional, espacios para la participación ciudadana en la toma de decisiones.

De esta manera, la incidencia de las organizaciones en las políticas públicas tuvo un éxito sustancial proactivo. Mientras que las decisiones tomadas -en especial por el Gobierno nacional- no fueron exitosas, ya que, aunque aparentemente se dieron soluciones a cada una de las demandas, estas no se cumplieron durante los gobiernos de turno, sino incluso siete años después de agendado el tema, por ejemplo, con la promesa de crear una estación de Policía del Magdalena Medio. Sin embargo, ahondar en esto correspondería más a una evaluación de política pública.

Tanto las políticas actuales de seguridad y convivencia ciudadana desde el enfoque de buen gobierno, como los planes de desarrollo desde el 2001 a la actualidad, se caracterizan por dar especial énfasis al fortalecimiento de la participación ciudadana, en el que se evidencia un reconocimiento del Estado, las organizaciones sociales y los líderes sociales como elementos claves para el mejoramiento de la convivencia. Sin embargo, adolece de políticas claras de seguridad ciudadana, a partir de, por ejemplo, la capacitación de los miembros de la fuerza pública como los encargados de establecer el orden y la seguridad, por lo cual, las políticas se concentraron más en la participación de la comunidad que en el fortalecimiento de la soberanía estatal, en donde se evidenciaron las mayores deficiencias.

A partir de lo expuesto, es importante señalar que si bien la investigación demuestra que la acción colectiva es un mecanismo de incidencia en la formulación de las políticas públicas, esto plantea nuevos interrogantes sobre su participación dentro de las otras fases del ciclo de dichas políticas como son la implementación, el monitoreo y evaluación de los resultados e impacto. Así mismo, plantea interrogantes como: ¡es la acción colectiva el medio más eficaz para que la ciudadanía pueda incidir en las políticas públicas? ¿El uso de este mecanismo puede ser un indicador de falencias en la democracia representativa? ¿El contexto de violencia es directamente proporcional al éxito de la acción colectiva?

\section{REFERENCIAS}

Ardila, J. (2001), Plan de Desarrollo Municipal "Barrancabermeja, una oportunidad para la Paz (2001-2003)". Barrancabermeja.

Decreto 1747 de 2002 [Alcaldía de Barrancabermeja]. Comité Intersectorial por la Defensa de la Vida. 2002.

Barrios, M. (2012). Masacre del 16 de mayo de 1998: una estrategia de control social en Barrancabermeja, un municipio con historia de acción social colectiva. Documento de trabajo 19. Bogotá: CERAC.

Bueno, E. (2012-2015). Plan de Desarrollo Municipal "En Barrancabermeja el futuro se construye hoy" (2012-2015). Barrancabermeja.

Centro de Memoria Histórica (s. f.) ¡Basta ya! Base de datos. Recuperado de http://www.centrodeme- 
moriahistorica.gov.co/micrositios/informeGene$\mathrm{ral} /$ basesDatos.html

Concejo Municipal de Barrancabermeja (1998). Conformación Concejo Municipal de Paz. Acuerdo 016 de 1998.

Concejo Municipal de Barrancabermeja (2006). Asignación de un Asesor de Paz y Convivencia. Decreto 061 de 2006.

Concejo Municipal de Barrancabermeja (2009). Declaración del 16 de mayo como el "Día municipal de la conmemoración de las víctimas de las violaciones de los derechos humanos y el derecho internacional humanitario", Acuerdo 011 de 2009.

Conformación Concejo Municipal de Paz (2001). Acuerdo 008 del 2001. Barrancabermeja.

Contreras, C. (2008). Plan de Desarrollo Municipal "Donde el amor es clave" (2008-2011). Barrancabermeja.

Cote, E. (2004). Plan de Desarrollo Municipal "Con honestidad haremos más por Barrancabermeja" (2004-2007). Barrancabermeja.

Dávila, A. (2010). La violencia en el Magdalena Medio. Análisis de la dinámica espacial. Bogotá: Ediciones Uniandes.

De la Garza Talavera, R. (2011). Las teorías de los movimientos sociales y el enfoque multidimensional. Estudios políticos (22), 107-138.

Departamento Nacional de Planeación (DNP) (2001). Política nacional de seguridad y convivencia ciudadana. Bogotá: DNP.

El Colombiano (1998a). "No eran de los nuestros: guerrilla”, p. 13A. El Colombiano.

El Colombiano, (1998b). "El Gobierno se comprometió con el desarrollo de Barranca", p. 13A. El Colombiano.

El Espectador (1998a). "La primera oleada de llanto en Barranca”. El Espectador.
El Espectador (1998b). "Peticiones de los desplazados". El Espectador.

El Espectador (1998c). "La comisión no tiene certeza de lo aquí afirmado". El Espectador.

El Espectador (1998d). "Rebotan problemas de desplazados a Pastrana”. El Espectador.

El Espectador (1998e). "Fiscalía tras líder de masacre en barranca”. El Espectador.

Favela, D. M. (2006). Protesta y reforma en México. Interacción entre Estado y sociedad 1946-1997. México: unam / Plaza y Valdez.

Gónzalez Gil, A. (2006). Acción colectiva en contextos de conflictividad violenta: una propuesta para su interpretación. Circunstancia (10). Recuperado de http://www.scielo.org. $\mathrm{mx} /$ scielo.php?script=sci_arttext\&pid=S018516162011000100007\&lng=es\&tlng=es.

Keck, M., Sikkink, K. y Murillo, L. (1999). Redes transnacionales de cabildeo e influencia. Foro Internacional, 39 (4), 404-428.

López, M. A. (2012). Los movimientos sociales y su influencia en el ciclo de políticas públicas. Región y Sociedad, 55, 159-197.

Ministerio de Justicia y del Derecho (2014). Resumen ejecutivo. Mejoramiento, asistencia técnica y apoyo al Programa Nacional de Centros de Convivencia Ciudadana en los municipios en los que opera el programa. Bogotá: Ministerio de Justicia y del Derecho.

Ministerio del Interior de Justicia (2003). Mejoramiento y asistencia técnica y apoyo al Programa Nacional de Centros de Convivencia Ciudadana en los municipios donde opera. Recuperado de: https:// spi.dnp.gov.co/App_Themes/SeguimientoProyectos/ ResumenEjecutivo/resumene\%20ejecutivo\%20 CCC\%20DNP\%20Marzo\%2025\%202010.pdf

O’Donnell, G. (2002). Acerca de varias accountabilities y sus interrelaciones. En Peruzzotti, E. y 
Smulovitz, C. (eds.). Controlando la politica, ciudadanos y medios en las nuevas democracias latinoamericanas. Buenos Aires: Temas.

Parsons, W. (2007). Politicas públicas: una introducción a la teoría y a la práctica del análisis de politicas públicas. México: Flacso.

Peruzzoti, E. (2006). La política de accountibility social en América Latina. En Rendición de cuentas, sociedad civil y democracia en América Latina. México: Manuel Porrúa Editores.

Presidencia de la República. Decreto 1747 de 2002. Bogotá.

Roth, A. N. (2002). Políticas públicas. Formulación, evaluación e implementación. Bogotá: Ediciones Aurora.

Tarrow, S. (1998). El poder en movimiento. Los movimientos sociales, la acción colectiva y la politica. Madrid: Alianza Editorial.
Tudela, J. y Justo, A. (2013). ¿Publicar o morir? El fraude en la investigación y en las publicaciones científicas. Persona y bioética, 17 (1), pp 12-27.

Valles, M. (1999). Técnicas cualitativas de investigación social. Reflexión metodológica y práctica profesional. Madrid: Síntesis.

Vanguardia Liberal (1998a). "La protesta se hizo sentir". Vanguardia Liberal.

Vanguardia Liberal (1998b). "Entregarían pruebas de supervivencia de los 25 barranqueńos". Vanguardia Liberal.

Vanguardia Liberal (1998c) Encuentro en Bogotá para revisar compromisos con el Gobierno nacional. Vanguardia Liberal.

Vanguardia Liberal (1998d). "No quedará impune: Samper". Vanguardia Liberal. 